\title{
Analysis of occupational accidents with biological material among professionals in pre-hospital services
}

\author{
Adriana Cristina de Oliveira ${ }^{1}$ \\ Maria Henriqueta Rocha Siqueira Paiva²
}

\begin{abstract}
Objective: To estimate the prevalence of accidents due to biological material exposure, the characteristics and post-accident conduct among professionals of pre-hospital services of the four municipalities of Minas Gerais, Brazil. Method: A cross-sectional study, using a structured questionnaire that was developed to enable the calculation of prevalence, descriptive analysis and analytical analysis using logistic regression. The study included 228 professionals; the prevalence of accidents due to biological material exposure was $29.4 \%$, with $49.2 \%$ percutaneous, $10.4 \%$ mucousal, $6.0 \%$ non-intact skin, and $34.4 \%$ intact skin. Results: Among the professionals injured, those that stood out were nursing technicians (41.9\%) and drivers (28.3\%). Conclusion: Notification of the occurrence of the accident occurred in $29.8 \%$ of the cases. Percutaneous exposure was associated with time of work in the organization ( $O R=2.51,95 \%$ CI: 1.18 to 5.35 , $\mathrm{p}<0.017)$. Notification about accidents with biological material should be encouraged, along with professional evaluation / monitoring.

Descriptors: Emergency Medical Services; Accidents, Occupational; Exposure to Biological Agents; Patient Care Team.
\end{abstract}

\footnotetext{
${ }^{1} \mathrm{PhD}$, Associate Professor, Escola de Enfermagem, Universidade Federal de Minas Gerais, MG, Belo Horizonte, Brazil.

${ }^{2}$ Doctoral student, Escola de Enfermagem, Universidade Federal de Minas Gerais, Belo Horizonte, MG, Brazil. RN, Sistema de Atendimento Móvel de Urgência, Prefeitura Municipal de Belo Horizonte, Belo Horizonte, MG, Brazil.
} 


\section{Introduction}

In the everyday life of the health professional, various risks related to occupational activities can trigger a workplace accident. These are classified, according to their nature, as physical, ergonomic, chemical and biological $^{(1)}$.

Among the occupational risks, great emphasis has been given to the biological risks by researchers because they constitute the primary form of occupational exposure, when the direct or indirect manipulation of biological material (BM) results from health care ${ }^{(2-}$ 5). Exposure to BM by contact with bodily secretions / excretions or injuries caused by sharp instruments, can be vehicles of transmission of microorganisms present in the blood or other body fluids, when related to care of patients(5).

Particularly beginning in the 1980s, after the discovery of the acquired immunodeficiency syndrome virus, particular concern has been attributed to contamination risks for healthcare workers due to occupational exposure to BM, which is responsible for the transmission of hepatitis $B$ and $C$ virus and HIV, among others ${ }^{(6)}$.

Among the professionals who perform health care activities in emergency environments, workers in prehospital care (PHC) deserve attention because of the complexity of the activities such as suturing of vessels for traumatic amputation, containment of hemorrhages, central and peripheral vascular access, intubation and aspiration of tracheal and pleural drainage, among others, which could potentiate the exposure of these professionals to $\mathrm{BM}^{(7-13)}$.

However, the occurrence of occupational accidents involving exposure to BM among PHC professionals, unlike those related to hospital care, is not well known. In Brazil, few studies have examined the prevalence of workplace accidents by exposure to BM in this category, indicating a rate that varies from $19.8 \%$ to $58 \%$. However, each of these studies was performed in a single prehospital care service, with distinct objectives, which does not allow, in principle, an approach to the problems of this reality $(8-10,12,14)$. Systematic data constitute an important gap of knowledge about this theme.

Given the above, this study was proposed to estimate the prevalence of accidents due to biological material exposure, and the characteristics and postaccident conduct of the pre-hospital care professionals in the four municipalities of Minas Gerais.
This study, in addition to expanding knowledge about the theme, contributes by presenting an incentive for managers and employees to reflect with a view toward establishing a strategic plan with implementation of preventive measures and effective control of protecting the health of the worker, and consequently to minimize accidents of this nature.

\section{Methods}

This was a cross-sectional epidemiological study conducted with professionals from the Public Service Mobile Urgent Care (Serviço Público de Atendimento Móvel de Urgência) of four cities in the state of Minas Gerais, deployed for over a year, and covering a population in excess of 100,000 inhabitants.

Subjects eligible for this study were physicians, nurses, technical and auxillary nurses, and drivers that worked in mobile units and performed direct care to the user of this service for more than one year.

We used a structured questionnaire that included demographic questions, knowledge about the characteristics of the accident with exposure to BM, and post-accident conduct.

After prior appointment with the local coordinator of each municipality, direct contact was made with each professional to present the objectives of the study, the importance of the results for further development and understanding of this theme, and the possible repercussions for the health of the worker. During this same contact, after agreement was received for participation in the research, the Term of Free and Informed Consent (TFIC) was signed by the participants. Data collection was conducted between October and November of 2011, and referred to occupational exposures that occurred in 2010. The collected data were entered into an Excel spreadsheet and analysis was performed using the Statistical Package for Social Sciences (SPSS), version 15.0.

The characterization of the population was verified by calculating absolute frequencies and percentages. After analyzing the distribution of the quantitative variables (age and time working in the institution) they were dichotomized using a cutoff value of their medians.

For bivariate analysis the chi-square test was used to evaluate comparisons of the qualitative variables and, when necessary, inference using the chi-square test via Monte Carlo simulation was used. In this first phase, the odds ratio (OR), confidence interval of $80 \%$ and a significance level of $20 \%(p<0.2)$ were used as a measure of strength of association. 
For the multivariate model a logistic regression technique was employed, verifying the influence of qualitative variables, that had a $p<0.2$ in the bivariate analysis, using the Odds Ratio (OR) as a measure of the strength of association, a confidence interval of $95 \%$ and a significance level of $5 \%(p<0.05)$.

This project, with its foundation in Resolution 196/96 of the National Health Council, was submitted along with the respective TFIC, to the Ethics in Research Committee of the Universidade Federal de Minas Gerais, and was approved under Opinion No. ETIC 503/2011.

\section{Results}

There were 249 professionals who worked in multidisciplinary teams of the four cities eligible for this study. Of these, $228(91.5 \%)$ participated in this research; the reason given for non-participation included: one formal refusal after meeting and explanation of the objectives, eight professionals were on vacation, six were on sick leave, and six did not work during the period of data collection.

The participant population included physicians $(23.7 \%)$, professional nurses $(11.0 \%)$, technical nurses (35.1\%) and drivers (30.2\%). A predominance of male workers $(63.2 \%)$ was noted, $58.1 \%$ were under the age of 37 years (24-60 years), and $58.3 \%$ had work experience in the institution less than four years and eleven months (1-8 years). The largest concentration worked in units of basic life support (59.3\%), with $40.7 \%$ of workers in units of advanced life support.

The prevalence of occupational accidents involving BM among PHC professionals in 2010 was $29.4 \%$ $(67 / 228)$, and of these $49.2 \%(33 / 67)$ of exposures were referred to as percutaneous; $10.4 \%$ (7/67) were mucosal; $6.0 \%$ (4/67) occurred with broken skin; and in $34.3 \%$ (23/67) with intact skin. Characteristics of the exposed workers are described in Table 1.

Table 1 - Characteristics of the professionals of the prehospital service exposed to occupational accidents involving biological material, according to demographic data. Minas Gerais, Brazil, 2011

\begin{tabular}{lcc}
\hline \multicolumn{1}{c}{ Variables } & $\mathbf{n = 6 7}$ & $\%$ \\
\hline Professional category & & \\
Physician & 14 & 20.9 \\
Nurse & 6 & 8.9 \\
Technical Nurse & 28 & 41.9 \\
Driver & 19 & 28.3
\end{tabular}

(continue...)
Table 1 - (continuation)

\begin{tabular}{lcc}
\hline \multicolumn{1}{c}{ Variables } & $\mathrm{n}=67$ & $\%$ \\
\hline Gender & 25 & 37.3 \\
Female & 42 & 62.7 \\
Male & & \\
Age & 39 & 58.2 \\
$\leq 37$ years & 28 & 41.8 \\
$>37$ years & & \\
Time working in the institution & 36 & 53.7 \\
$\quad \leq 4$ years and 11 months & 31 & 46.3 \\
$>4$ years and 11 months & & \\
Unit specialty & 39 & 58.2 \\
Basic Support Unit & 28 & 41.8 \\
$\quad$ Advanced Support Unit & & \\
\hline
\end{tabular}

The accidents involving percutaneous exposures totaled 33 in 2010, of which $62.5 \%$ (21/33) of the professionals reported having only one occurrence, followed by $34.4 \%$ (11/33) twice, and 3.1\% (1/33) more than four times. The handling of material impregnated by blood, such as hollow needles (58.2\%), glass vials $(19.3 \%)$, lancets $(9.6 \%)$ and suture needles, metal, blades and intravenous catheters in equal proportion (3.2\%) were cited by workers, with the fingers (50.0\%) and hands (25.0\%) being the worst affected areas.

With regard to the care activities related to percutaneous exposure, these included: performing venipuncture $(34.6 \%)$; capillary glucose collection $(30.4 \%)$, intradermal medication and needle recapping $(11.5 \%)$; suturing $(7.6 \%)$; intramuscular medication and intravenous catheter withdrawal in $2.2 \%$ of cases, respectively.

Mucosal exposure was observed in seven occupational accidents, with $57.1 \%$ of respondents reporting that this type of event occurred twice during the year 2010, while others (42.9\%) noted three times. The agents involved in the majority of cases were blood (58.4\%) and vomit (16.6\%). Sweat, amniotic fluid and tracheal aspirates were also cited in $3.6 \%$ of cases. The contact areas referred to by most workers were the ocular mucosa $(66.6 \%)$, followed by nasal and oral, in $16.7 \%$.

Among the activities listed by healthcare workers at the time of the accident involving mucosal exposure to biological fluids, disposal of surgical specimens (37.5\%), childbirth assistance $(25.0 \%)$, orotracheal intubation $(25.0 \%)$ and packaging waste $(12.5 \%)$ produced during emergency care were all mentioned.

Contact with broken skin totaled four occupational accidents, with blood being the only body fluid involved. Of these, $50 \%$ occurred once, $25 \%$ occurred twice, 
and the remaining $25.0 \%$ occurred three times. The body areas affected were similarly hands and fingers. Immobilization of the patient for transport (75.0\%) and disposal of surgical materials (25.0\%) were cited as the activities being undertaken by workers at the moment of contact.

Occupational accidents involving contact with body fluids with intact skin exposures totaled 23 in 2010; of these blood was found in $90.3 \%$, vomit in $4.3 \%$, tracheal secretions in $3.2 \%$, and amniotic fluid in $2.2 \%$ of cases. Among the professionals who reported this type of event, $75.0 \%$ of them reported the occurrence of three or more exposures, with the arms (32.2\%), hands (23.2\%) and face $(14.3 \%)$ being the most affected regions. Further, it was observed that the fingers $(7.2 \%)$, feet $(2.5 \%)$, legs $(2.5 \%)$, mouth $(2.5 \%)$, chest $(2.5 \%)$, head $(1.2 \%)$ and knees $(1.2 \%)$ were also exposed to body fluids, in smaller proportions.

The care activities performed at the time of contact, as cited by those professionals having the accidents, suggested the exposure trigger in $41.0 \%$ of cases was patient immobilization, followed by: cleaning the material used (18.2\%); orotracheal intubation (13.6\%); assistance with childbirth and mechanical restraint of the patient being assisted ( $9.1 \%$ for each); fixing an oxygen mask to the patient>s face, and packaging residue produced during care ( $4.5 \%$ each).

With regard to personal protective equipment (PPE) when the accident occurred, $89.6 \%$ of the professionals reported they were using nonsterile gloves, $68.6 \%$ the institutional uniform, and $50.7 \%$ high boots. Regarding the concomitant use of uniform, protective goggles, face mask, high boots and nonsterile gloves, at the time of the occupational accident, only $10.4 \%$ of workers reported the use of these items simultaneously.

Regarding the recommended measures immediately post-accident, $38.8 \%$ of the professionals injured had a medical evaluation performed by a specialist, but the occupational injury report (OIR) was issued in only $29.8 \%$ of cases. Serology for HIV and hepatitis B and C postoccupational accident and source was not performed in $68.6 \%, 73.1 \%$ and $74.6 \%$ of the cases, respectively. Serology following the exposed professionals for a year to assess the possibility of transmission of the AIDS virus and hepatitis B was not performed in $95.5 \%$ of cases, and for hepatitis $C$ it was not performed for any professional.

In bivariate analysis between the occurrence of accidents by contact with BM and the demographic variables, we found that percutaneous exposure was statistically associated with age $(p=0.185)$ and time working in the institution $(p=0.015)$. Multivariate analysis showed that only the time working in the institution maintained a statistical relationship with percutaneous exposure to BM (OR $=2.51,95 \% \mathrm{CI}: 1.18$ to $5.35, p=0.017)$. Thus, it was found that the chance of occupational accidents involving the percutaneous method was 2.5 times higher among employees who had worked at the institution for more than four years and eleven months.

\section{Discussion}

In this study, there was a predominance of male professionals $(65.5 \%)$, which was consistent with other research with prehospital care workers $(7,9,13-14)$, except for a follow-up conducted in the state of Goiás that noted a majority of females $(57 \%)^{(10)}$.

The overall prevalence of occupational accidents involving BM was $29.4 \%$, but among the participating cities it ranged from $20.2 \%$ to $38.5 \%$. Unlike what was observed in previous studies with PHC professionals in other locations in the state of Minas Gerais, where the variation of the accidents was $19.8 \%$ to $20.6 \%{ }^{(9,14)}$. It also varied from those found in research conducted with fire department professionals of a city in the state of Goiás (40\%) in 2003(8); and between PHC professionals and firefighters of Goiás, who worked together in the prehospital care in 2007. In this study, the prevalence was $57 \%$ for professional physicians, nurses and technical nurses; for drivers and firefighters it was $43.0 \%{ }^{(10)}$.

The majority of accidents involved the technical nurses $(41.9 \%)$; this result was dissimilar to that observed in other studies with a multidisciplinary PHC team. Among PHC professionals in Goiás, professional nurses were highlighted $(28.7 \%)^{(10)}$; in Belo Horizonte, $35.3 \%$ of cases were observed among physicians and $24.0 \%$ among professional nurses(9); and in the metropolitan region of Belo Horizonte, $33.3 \%$ were recorded among physicians and $24 \%$ among drivers ${ }^{(14)}$.

The technical and auxillary nurses are the professional category generally more associated with occupational accidents involving exposure to BM, either due to their intense activity together with critical patients, long hours of work, the stressful routine, or even for the greatest number of cares provided by the USB, the composition of the care team includes these professionals.

This study highlighted occupational accidents in which percutaneous exposure to BM occurred. This 
finding was similar to results found in a survey conducted among PHC professionals in the city of Campinas, São Paulo, where the prevalence of these events was $28.6 \%{ }^{(13)}$. In other studies, exposures with body fluids that were unrelated to the handling of sharps prevailed, with variation between $49.0 \%$ to $70.7 \%$ of $\operatorname{cases}^{(9,12,14)}$

It is important to note that the activities provided by PHC healthcare professionals mostly involve assistance to victims of trauma who present with bleeding, assistance with childbirth with consequent release of amniotic fluid, as well as situations related to sudden illness and exogenous intoxication with frequent elimination by vomiting. The constant presence of these fluids during health care performed under stressful condition and an elevated level of anxiety may potentiate the possibility of worker exposure(13).

After exposure to BM, the risk of transmission of pathogens carried by body fluids is variable and depends on the type of accident, severity, presence of associated injuries, presence and volume of blood involved, the clinical conditions of the source patient, and the acceptability and correct post-exposure

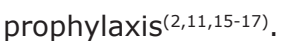

In the PHC, the concurrent use of institutional uniform, protective goggles, face mask, high boots and nonsterile gloves throughout the care is recommended $(2,6)$. The institutional uniform is considered to be required equipment. In this study when we evaluated the institutional uniform, as one of the PPE used by workers at the moment of the occupational accident, not all professionals indicated its use. During the data collection it was possible to observe that all professionals used the institutional uniform, which allowed for the inference that for a portion of these individuals, there was no recognition of this equipment as a way to promote the protection of the worker.

As to the mechanisms of exposure related to the occurrence of accidents described by professionals, it was verified that blood was the element most involved in all types of exposure. Accidents with perforations by hollow needles containing blood are considered serious accidents, subject to assessment, serological monitoring and indication of chemoprophylaxis. While many health professionals disregard BM accidents involving intact skin, these can contain microdamage that can serve as a gateway for entry of infectious agents, including HBV, HCV and HIV(15-17).

The immobilization of the patient was the care activity most frequently cited by professionals as a facilitating factor in the exposure of intact skin of the professional to the BM. This result differed from a study conducted with PHC staff in the city of Goiânia, state of Goiás, in which this activity was highlighted by only $6.8 \%$ of workers ${ }^{(10)}$. The moment of immobilization the trauma victim is crucial, demanding attention, skill and technique, because of the risk of complications of the initial condition of the patient. For example, a minimal injury in the vertebral column can result in complex neurological damage and can compromise the progress of the patient, and especially his prognosis.

In relation to specialist medical consultation and subsequent issuance of the statement of occupational accident, post-accident research conducted with $\mathrm{PHC}$ professionals from other cities in the states of Minas Gerais and Goiás reinforced the results obtained by this study, recording a mean of $22.7 \%$ (no medical evaluation $-36.7 \%$ of cases) and a mean of $9.0 \%$ (no - $18.4 \%$ of cases) in the issuance of the OIR, which is considered mandatory ${ }^{(8-9,14)}$.

The post-accident medical assessment is essential for the analysis of the severity of the exposure, solicitation of serological tests for hepatitis B, C and HIV, prescription and indication of chemoprophylaxis. Failure to complete the OIR mischaracterizes the possibility of an association between exposure to BM and the occurrence of the accident, as well as the development of occupational illness.

Regarding variables statistically associated to the percutaneous occupational exposure among $\mathrm{PHC}$ professionals, only time working in the institution was identified as a likely predictive factor. In this respect it is inferred that the professional feels more confident in carrying out his activities over a length of time working in the service, which may favor unsafe behavior that can often contribute to the occurrence of accidents. The results obtained in this study provided evidence that being a professional who had provided services for the longest time in PHC was not sufficient to prevent or reduce the risk of occurrence of occupational accidents.

\section{Conclusions}

The present study showed that the multidisciplinary team, based on its demographic data, consisted of physicians, nurses, technical nurses, and drivers, mostly of the male gender, assigned to USB, aged less than 37 years, and work experience in the institution of more than 4 years and 11 months.

Among the professionals injured involving BM in 2010, technical nurses and drivers were predominant. 
Regarding the possibility of transmission of pathogens carried by body fluids, the majority of accidents referred to by the professionals involved percutaneous exposure, followed by mucous membranes and broken skin.

In accidents related to handling of sharps materials, a greater number of professionals reported these had occurred only once in the year investigated, and the fingers and hands were the areas most affected by these devices. Of the exposures caused by contact with bodily fluids, a large part of the professionals reported having had four or more exposures, and the arms, hands and eyes were the most affected regions.

Regarding post-accident conduct, most professionals did not have a medical assessment performed after an occurrence, and consequently the OIR was not issued. For most injured workers, no immediate post-accident conduct regarding the possibility of transmission of hepatitis B, C and HIV occurred, and consequently the serological monitoring of that worker for a year postevent did not occur.

In view of the results obtained in this study, and considering the dearth of research analyzing occupational accidents with exposure to BM between employees of the Serviço de Atendimento Móvel de Urgência, the importance of reporting the accident with biological material and evaluation and monitoring of occupational exposure is underscored.

\section{References}

1. Marziale MHP, Nishimura KYN, Ferreira MM. Contamination risks caused by occupational accidents with cutting and piercing material among nursing workers. Rev. Latino-Am. Enfermagem. 2004;12(1):36-42.

2. Ministério da Saúde (BR). Riscos biológicos - Guia Técnico. Os riscos biológicos no âmbito da norma reguladora n. 32. Brasília (DF): Ministério da Saúde; 2008.

3. Canini SRMS, Gir E, Machado AA. Accidents with Potentially Hazardous Biological Material among Workers in Hospital supporting services. Rev. Latino-Am. Enfermagem. 2005;13(4):486-500. Inglês.

4. Azap A, Ergonul O, Memikoglu KO, Yesilkaya A, Altunsoy $A$, Bozkurt GY, et al. Occupational exposure to blood and body fluids among health care workers in Ankara, Turkey. Infect Control Hosp Epidemiol. 2005;33(1):51-2. Inglês.

5. Bálsamo AC, Felli VEA. Study of work accidents related to human body fluids exposure among health workers at a university hospital. Rev. Latino-Am. Enfermagem. 2006;14(3):39-45.

6. Siegel JD, Rhinehart E, Jackson M, Chiarello L, and The Healthcare Infection Control Practices Advisory Committee. 2007 Guideline for Isolation Precautions: Preventing Transmission of Infectious Agents in Healthcare Settings, June 2007.[acesso 19 dez 2011]; Disponível em: http://www.cdc.gov/ncidod/dhqp/pdf/ isolation2007.pdf. Inglês.

7. Zapparoli AS, Marziale MHP. Risco ocupacional em unidades de Suporte Básico e Avançado de Vida em Emergências. Rev Bras Enferm. 2006;59(1):41-6.

8. Florêncio VB, Rodrigues CA, Pereira MS, Souza ACS. Adesão às precauções padrão entre os profissionais da equipe de resgate pré-hospitalar do Corpo de Bombeiros de Goiás. Rev Eletrônica Enferm. [periódico na Internet]. 2003 [acesso 8 mar 2012];5(1). Disponível em: http://www.fen.ufg.br/revista/re vista5_1/adesao.html.

9. Lopes ACS, Oliveira AC, Silva JT, Paiva MHRS. Adesão às precauções padrão pela equipe do atendimento préhospitalar móvel de Belo Horizonte, Minas Gerais, Brasil. Cad Saúde Pública. 2008;24(6):1387-96.

10. Silva EAC. Risco biológico para os trabalhadores que atuam em serviços de atendimento pré-hospitalar [dissertação de mestrado]. Goiânia (GO): Faculdade de Enfermagem da Universidade Federal de Goiás; 2007. $107 \mathrm{p}$.

11. Pereira ACM, Silva AR, Rocha CF, Cordeiro IS, Lopes CM. Work accidents with needles and other sharp medical devices in the nursing team at public hospitals - Rio Branco, Acre - Brazil. Online Braz J Nurs. [online]. 2004[acesso 8 mar 2012];3(3). Disponível em: www. uff.br/nepae/objn303pereiraetal.htm.

12. Soerensen AA, Moriya TM, Hayashida M, Robazzi MLCC. Acidentes com material biológico em profissionais do Atendimento Pré-hospitalar Móvel. Rev Enferm UERJ. 2009;17(2):234-9.

13. Vegian CFL, Monteiro MI. Living and working conditions of the professionals of the a Mobile Emergency Service. Rev. Latino-Am. Enfermagem. 2011;19(4):1018-24. Inglês, Português.

14. Paiva MHRS, Oliveira AC. Fatores determinantes e condutas pós-acidente com material biológico entre profissionais do atendimento pré-hospitalar. Rev Bras Enferm. 2011;64(2):268-73.

15. Ministério da Saúde (BR). Secretaria de Atenção à Saúde, Departamento de Ações Programáticas Estratégicas, Exposição a materiais biológicos. Brasília (DF): Ministério da Saúde; 2006. 
16. Toledo AD, Oliveira AC. Situação vacinal e sorológica para hepatite $B$ entre trabalhadores de uma unidade de emergência. Rev Enferm UERJ. 2008;16(1):95-100.

17. Paiva EMM. Soroprevalência da infecção pelo vírus da hepatite $\mathrm{B}$ e avaliação da imunidade vacinal em cirurgiões-dentistas de Goiânia - GO [tese de doutorado]. Goiânia (GO): Universidade Federal de Goiás; 2008. 140 p. 